CONF- $951155-119$

UCRL-JC-1229.57

PREPRINT

\title{
Magnetic Coupling in Spin-Valves from Magnetic Circular Dichroism
}

\author{
P.J. Bedrossian \\ J.G. Tobin \\ G.D. Waddill \\ A.F. Jankowski \\ T.C. Anthony \\ J.A. Brug
}

This paper was prepared for submittal to the

Fall Meeting of the Materials Research Society

Boston, MA

November 27 tö December 2, 1995

December 18, 1995

This is a preprint of a paper intended fơ publicationitin a joüunal or proceeatings. Since changes may be made before publication, this preprint is made aviliable with the understanding that it will not be cited or reproduced without the permission of the author. 


\section{DISCLAIMER}

This document was prepared as an account of work sponsored by an agency of the United States Government. Neither the United States Government nor the University of California nor any of their employees, makes any warranty, express or implied, or assumes any legal liability or responsibility for the accuracy, completeness, or usefuliness of any information, apparatus, product, or process disclosed, of represents that its use would not inifringe privately ovined rights. Reference herein to any specific commercial product, process; or service by trade name, trademark, manufacturer, or otherwise, does not necessarily constitute or imply its endorsement, recommendation, or favoring by the United States Government or the University of California: The views and opinions of authors expressed herein do not necessarily:state or reflect those of the United States Governinent or the University of-California, and shall not be used for advertistng or product endorsement purposes. 


\section{DISCLADMER}

Portions of this document may be illegible in electronic image products. Images are produced from the best available original document. 
Magnetic Coupling in Spin-Valves from Magnetic Circular Dichroism

\author{
P. J. Bedrossian1, J. G. Tobin 1, G. D. Waddill2, A. F. Jankowski1, \\ T. C. Anthony 3 , and J. A. Brug 3 \\ (1) Lawrence Livermore National Laboratory, Livermore CA 94550 \\ (2) University of Missouri-Rolla, Rolla MO 65401 \\ (3) Hewlett-Packard Laboratories, Palo Alto Ca 94305
}

Spin valves, consisting of two, coupled magnetic films separated by a thin ( $<30 \AA)$ spacer layer, offer the oscillatory magnetic coupling of giant magnetoresistance (GMR) devices but with greatly reduced saturation fields as compared with multilayer structures. Because the optimization of spin valve performance depends on precise control of the magnetic moments of coupled layers, the reliable, quantitative measurement of the moments of the constituent elements in the device is critical. The elemental specificity of magnetic circular dichroism (MXCD) in $L$-edge $\mathrm{x}$-ray absorption offers the means to detect the magnetic moments of each component of such devices and has already been applied extensively to extract magnetic moments in multilayers. ${ }^{1-4}$

We have applied magnetic $\mathrm{x}$-ray circular dichroism $(\mathrm{MXCD})$ to extract elemental magnetic moments for real, thin-film spin valve devices and demonstrated the correlation between $\mathrm{MXCD}$ and $\mathrm{R}-\mathrm{H}$ measurements on those devices. The spin valves consisted of $\mathrm{NiFe} / \mathrm{Co} / \mathrm{Cu} / \mathrm{Co} / \mathrm{NiFe}$ sandwiches with variable $\mathrm{Cu}$ spacer-layer thickness, grown on a thick $\mathrm{NiO}$ film, as described previously. 5 One permalloy layer is therefore magnetically pinned to the substrate which it contacts.

Spin-polarized, X-ray absorption spectra were collected using beamline 8-2 at the Stanford Synchrotron Radiation Laboratory. The Poynting vector of the incident beam was aligned at grazing incidence to the films, either parallel or antiparallel to their remanent magnetization. For each spin valve, 
four absorption spectra were collected. With the remanent magnetization initially parallel to the incident beam direction, a pair of spectra were recorded, one with the helicity of the incident photons parallel to the remanent magnetization of the device, and one with their helicity antiparallel to the remanent magnetization. Next, the samples were rotated in order to align their remanent magnetization antiparallel to the incident beam direction, and a pair of absorption spectra was similarly obtained from beams polarized with opposite helicity. Finally, each absorption spectrum was normalized to the incident photon flux.

Figure 1 displays one pair of normalized spectra acquired using opposite photon helicities, as indicated, with the remanent sample magnetization parallel to the incident beam direction. Strong white lines are evident at the $L$ edges of $\mathrm{Fe}, \mathrm{Co}$, and $\mathrm{Ni}$, whereas the $\mathrm{Cu}$ edge signal from the thin, spacer layer occurs in the region dominated by the Ni EXAFS signal. Each pair of white lines for a particular element in fig. 1 exhibits a strong dependence of relative intensity on incident beam helicity.

Research was performed at Lawrence Livermore National Laboratory under the auspices of the US Dept. of Energy under Contract W-7405-Eng48, and at Hewlett-Packard Laboratories.

\section{Figures}

1. Pair of normalized absorption spectra from a spin valve sample, one acquired using a beam helicity parallel, and one antiparallel, to the remanent magnetization. $L$ absorption edges are indicated. 


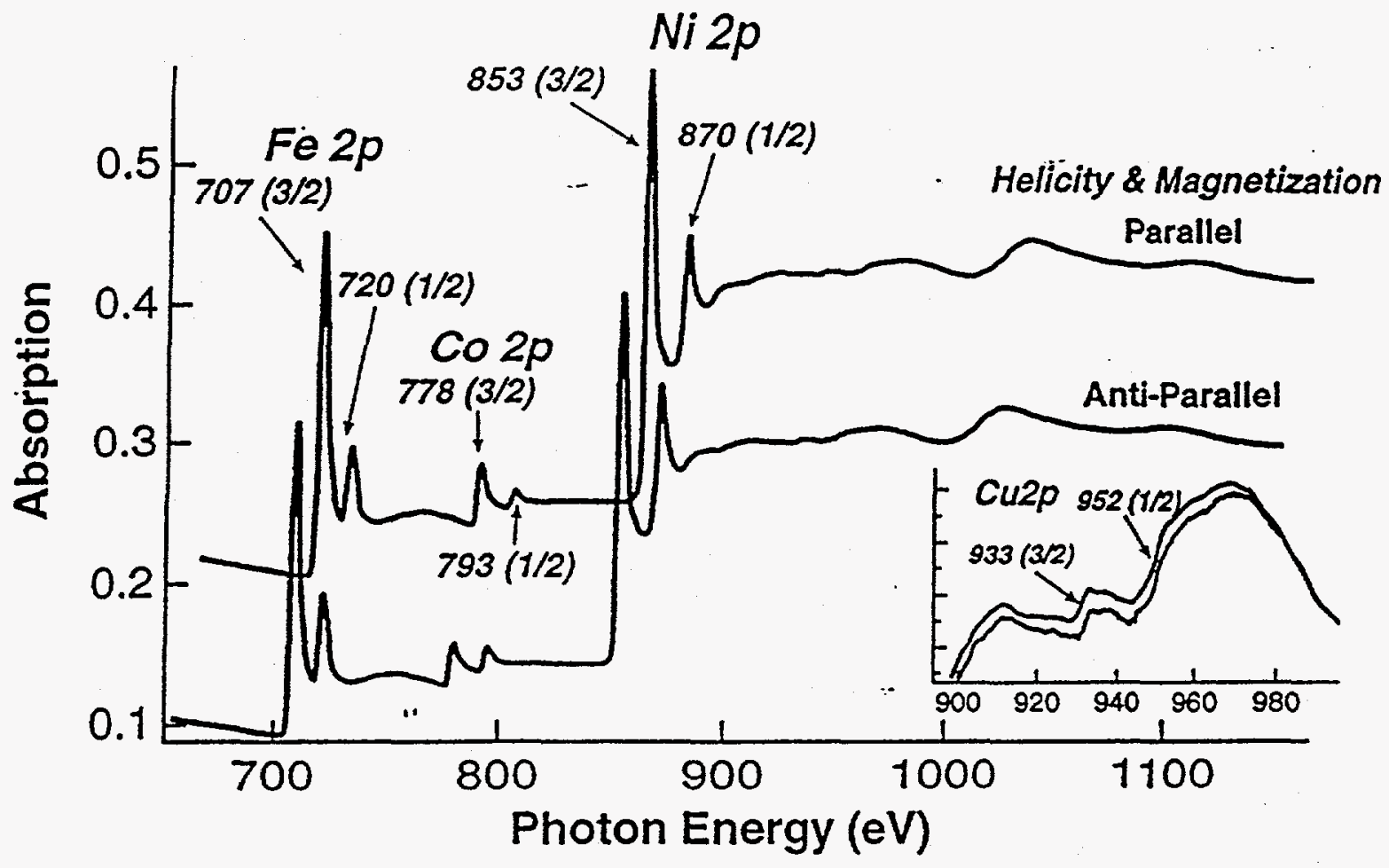

References

1. J. Stöhr and Y. Wu. in New Directions in research with $3 r d$ Generation Soft X-ray Synchrotron Radiation Sources (eds. Schlacter, A. \& Wuillemier, F.) (Kluwer Academic, Dordrecht; Boston, 1994).

2. A. Jankowski, G. Waddill and J. Tobin. J. Vac. Sci. Technol. A 12, 2215-2218 (1994).

3. Y. Wu, et al. Phys. Rev. Lett. 69, 2307-2310 (1992).

4. G. Waddill, J. Tobin and A. Jankowski. J. Appl. Phys. 74, $6999-$ 7001 (1993).

5. T. Anthony, J. Brug and S. Zhang. IEEE Trans. Mag. 30, 3819 (1994). 